\title{
ARTESANATO E MÍDIA: QUANDO O MIDIÁTICO ATRAVESSA O TRADICIONAL
}

\author{
Crafts and Media: when the media surpasses the traditional
}

\section{Artesanía y Medios: Cuando lo mediático atraviesa lo tradicional}

Denise Figueiredo Barros do Prado Professora do Departamento de Jornalismo e do Programa de Pós-Graduação em Comunicação da Universidade Federal de Ouro Preto denisefbp@gmail.com

\section{Resumo}

Neste artigo, discute-se como as produções artesanais revelam articulações entre a cultura popular e o midiático a partir da observação e análise do artesanato de Mariana (MG). Isto se deve à percepção de que tais produções são fortemente vinculadas à cultura midiática, especialmente pela incorporação de personagens de HQs famosos e desenhos animados (como Minions, Homem Aranha e Galinha Pintadinha). Entende-se que o surgimento deste tipo de produção artesanal se constitui como um fenômeno privilegiado para a compreensão da forma como o contexto midiático contemporâneo é processado e articulado às práticas culturais populares. Para entender este cenário, buscamos as contribuições de Canclini (2015), relativos à hibridização, e Certeau $(2008,2009)$ sobre as práticas culturais, entre outras contribuições teórico-conceituais.

Palavras-chave: Artesanato. Cultura midiática. Práticas culturais.

\begin{abstract}
In this article, it is discussed how craft productions reveal the connections between popular and media culture based on the observation and analysis of the craft of Mariana (MG). This is due to the perception that such productions are strongly linked to the media culture, especially by the incorporation of characters of famous comics and cartoons (for instance Minions, Spiderman and Galinha Pintadinha). It is understood that the emergence of this type of craft production constitutes a privileged phenomenon for the understanding of how the contemporary media context is processed and connected to popular cultural practices. To understand this scenario, we took into consideration the concepts of Canclini (2015), regarding hybridization, and Certeau $(2008,2009)$ on cultural practices, among other theoretical-conceptual contributions.
\end{abstract}

Key words: Craft. Media culture. Cultural practices.

\section{Resumen}

En este artículo se discute cómo las producciones artesanales revelan articulaciones entre la cultura popular y lo mediático, a partir de la observación y análisis de la artesanía de Mariana (MG). Esto se debe a la percepción de que tales producciones se revelan fuertemente 
vinculadas a la cultura mediática, especialmente por la incorporación de personajes de Tiras Cómicas y de dibujos animados (como Minions, el Hombre Araña y la Gallina Pintadita.) Se entiende que el surgimiento de este tipo de producción artesanal se constituye en un fenómeno privilegiado para la comprensión de la manera como el contexto mediático contemporáneo es procesado y articulado a las prácticas culturales populares. Para comprender este escenario, buscamos las contribuciones de Canclini (2015), relativos a la hibridación, y Certeau (2008, 2009) sobre las prácticas culturales, entre otras contribuciones teóricas-conceptuales.

Palabras clave: Artesanía. Cultura mediática. Prácticas culturales

\section{INTRODUÇÃO}

Este artigo se propõe a problematizar o artesanato. Sim, o artesanato, essa prática cultural entranhada no cotidiano e na memória: habitual e fácil, presença recorrente nas feiras populares e na decoração das casas. Uma prática que remonta a um passado-presente, com o qual temos contatos inesperados sem que nos surpreendam dada a sua familiaridade. Aliás, foi justamente por romper nossa relação habitual com o artesanato e a cidade que emergiu a inquietação tratada nesse artigo - uma questão que foi logo convertida uma pesquisa, realizada entre 2016 e $2018^{1}$.

Contextualizando nossa proposta, vale explicar que essa pesquisa surgiu a partir de nossa inserção social: morando em Mariana (MG), uma cidade histórica, Monumento Nacional, que recebe turistas de várias partes do Brasil e do mundo, somos convocados a pensar o lugar da história, do patrimônio e da arte; mas, não necessariamente da arte canônica que habita as igrejas e as construções barrocas. A nós, interessa-nos a arte do dia a dia, cotidiana, nascida da experiência dos que habitam a cidade. Eles dão vida à culinária, à pintura e ao artesanato, fazem centenas de souvenirs que vão ocupar espaços de decoração relembrando os turistas dos passeios familiares.

Num emaranhado de objetos de recordação, encontramos porta-joias, cinzeiros (cada vez mais raros), jarros, fruteiras, bonecas de pano, brinquedos em madeira, imagens de santos entalhados em madeira ou feitos de pedra sabão. Em meio a esses objetos, alguns brinquedos infantis nos chamaram a atenção: bonecos da Galinha Pintadinha ${ }^{2}$ e da Peppa $^{3}$ cerzidos em

\footnotetext{
${ }^{1}$ Essa pesquisa foi desenvolvida com o apoio da Universidade Federal de Ouro Preto e com a participação das estudantes bolsistas do projeto, Caroline Rook (PIP/UFOP - 2016/2017), Letícia Lopes (PIBIC/UFOP 2017/2018), Thalia Gonçalves (PIP/UFOP - 2017/2018) e Sabrina Vicentina de Jesus (FAPEMIG Jr. 2017/2018), e com a técnica em fotografia e planejamento visual Monique Campos, a quem sou grata.

${ }^{2}$ A Galinha Pintadinha é uma animação infantil brasileira, criada por Juliano Prado e Marcos Luporoni, cujos clipes envolvendo cantigas populares e ilustrados pela personagem foram divulgados no YouTube e se tornaram um grande sucesso nacional. Para dimensionar sua projeção, destacamos que o clipe de lançamento da personagem já foi visualizado 450 milhões de vezes no canal da franquia.
} 
tecido, cavalinhos de pau estampados com figuras do Batman, do Superman e de outros heróis das HQs ${ }^{4}$ e imãs de geladeira da turma do Chaves ${ }^{5}$. Com o olhar surpreso, fomos fisgados pela força do objeto. O discurso midiático aparece atravessando práticas artesanais locais dividindo o espaço com produtos considerados tradicionais, feitos em tecido, pedra sabão e madeira.

Podemos dizer que foi o affordance do objeto que nos convocou e atraiu. Quéré (2000), tomando de empréstimo o conceito de Gibson (quando de sua análise das reações perceptivas dos organismos vivos em seu ambiente), explica que todos os objetos são dotados de affordance, uma força de atração e afetação que convoca as pessoas a adotarem certos posicionamentos ou reações a partir do contato com eles. Essa convocação se trata tanto de uma característica do objeto, que o singulariza no ambiente, quanto de uma relação contextual que ele nutre com o conjunto ambiental e situacional no qual ele é apreendido. No caso em tela, é a força do destoante que nos atrai, que promove uma ruptura no senso de lugar, inserindo traços do midiático em um contexto marcado pelo tradicional. É a atratividade desses objetos, que fundem o moderno e o tradicional na sua constituição, que nos faz querer compreender as recorrências e reminiscências desse entrecruzamento de formas culturais.

A partir de uma primeira surpresa e esforço de assimilação dos objetos inscritos nas lojas de artesanato de Mariana, temos nossa atenção direcionada para essa característica singular: a presença do midiático atravessando o tradicional. Percebemos não só a aparição de outros personagens em brinquedos feitos em tecido e madeira (como Capitão América e Superman), como também notamos uma variedade de produtos vinculados à cultura midiática, como rótulos de cervejas em relógios de madeira, bonequinhos bebedores com pequenas réplicas de latas da cerveja Skol nas mãos e estampas feitas com a logomarca da cervejaria Heineken em porta copos.

\footnotetext{
${ }^{3}$ Peppa Pig é um desenho animado britânico, cuja personagem principal (a Peppa) é uma porquinha rosada. Essa animação alcançou grande sucesso mundial. Ela começou a ser exibida no Brasil em 2013, no canal a cabo Discovery Kids, e continua em exibição.

${ }^{4}$ Super heróis famosos nos HQs e no cinema - como Batman, Mulher Maravilha, Superman, Homem Aranha, Hulk, Homem de Ferro, Capitão América, entre outros - conquistam grande espaço entre as produções artesanais infantis. Tanto personagens famosos das franquias da Marvel quanto da DC Comics estão presentes nos materiais dessa pesquisa.

${ }^{5}$ Chaves é o personagem central da série televisiva homônima, criada por Roberto Gómez Bolaños, e produzida pela emissora mexicana Televisa na década de 1970. Essa série, exibida por mais de 30 anos no Sistema Brasileiro de Televisão (SBT) no Brasil, alcançou muito sucesso e é reconhecida como um marco televisivo. Atualmente, a série é exibida pelo canal Multishow, do Grupo Globo.
} 
A partir dessa percepção, realizamos um mapeamento nas lojas de artesanato da cidade de Mariana, com o intuito de criar um registro fotográfico das peças ali expostas e do seu contexto de exibição, e entrevistamos as artesãs responsáveis pelas produções artesanais locais. Há 13 lojas de artesanato registradas na cidade sendo que, desse total, dez efetivamente vendem peças artesanais ${ }^{6}$ e integraram nosso mapeamento. Também foram entrevistadas 18 artesãs sobre sua vinculação com as práticas artesanais, o processo de produção e sua relação com a cultura midiática.

Nesse mapeamento, foram encontrados cinco tipos de produções artesanais aqui exemplificados pelas figuras abaixo: (1) peças de reprodução das formas midiáticas, como aquelas que procuram recriar a forma dos personagens de desenhos infantis com técnicas artesanais (Figura1); (2) peças de incorporação de formas midiáticas retraduzidas em produtos artesanais, nas quais imagens midiáticas são incorporadas como adorno ou remetendo aos personagens, mas gerando formas novas (Figura 2), (3) peças que conjugam e mesclam traços midiáticos, mas sem vinculação imediata, pois sua utilização deriva da aprendizagem desenvolvida a partir da criação de peças associadas às imagens midiáticas - exemplo disso é o formato dos olhos da Galinha Pintadinha que passa a ser replicado em bonecas, corujas e outros tipos de peças (Figura 3); (4) peças geradas para atender a necessidades contemporâneas, como porta celulares, porta tablets entre outros (Figura 4) e (5) peças que foram criadas a partir do aprendizado de novas técnicas por meio de redes sociais digitais e interações midiatizadas (Figura 5).

Figura 1 - Imã de geladeira do Chaves

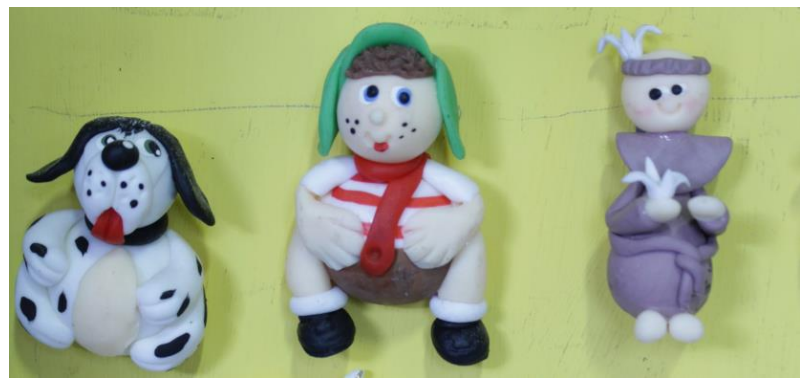

Fonte: Equipe de pesquisa (agosto/2016)

\footnotetext{
${ }^{6}$ Dentre as três lojas excluídas deste estudo, duas delas foram retiradas porque manifestaram que já não comercializavam mais peças artesanais, trabalhando somente com produtos industrializados. A terceira loja atua com a venda de joias, semijoias, cristais e pedras semipreciosas, fugindo do escopo do nosso estudo.
} 


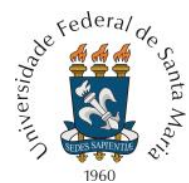

PROGRAMA DE PÓS-GRADUAÇÃO EM COMUNICAÇÃO DA UNIVERSIDADE FEDERAL DE SANTA MARIA

Figura 2 - Toucas de crochê remetendo aos Minions e à Pokebola (Pokémon)

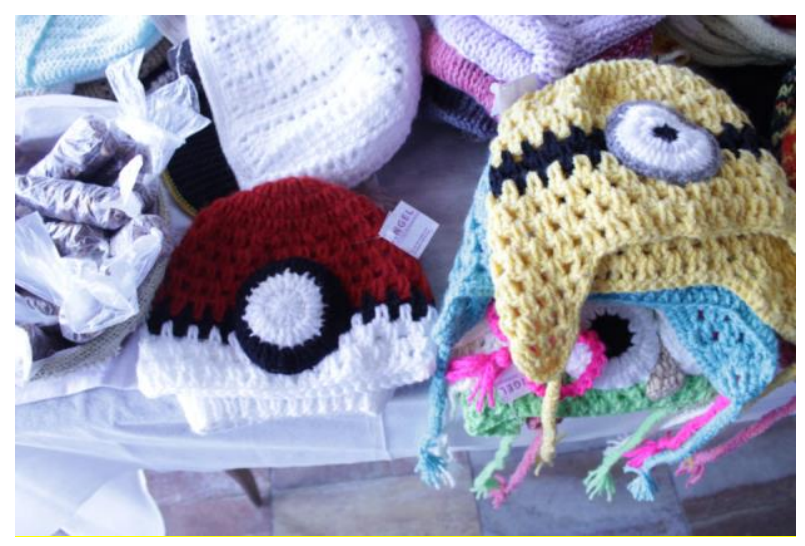

Fonte: Equipe de pesquisa (agosto/2016)

Figura 3- Coruja de feltro, com olhos inspirados na imagem da Galinha Pintadinha

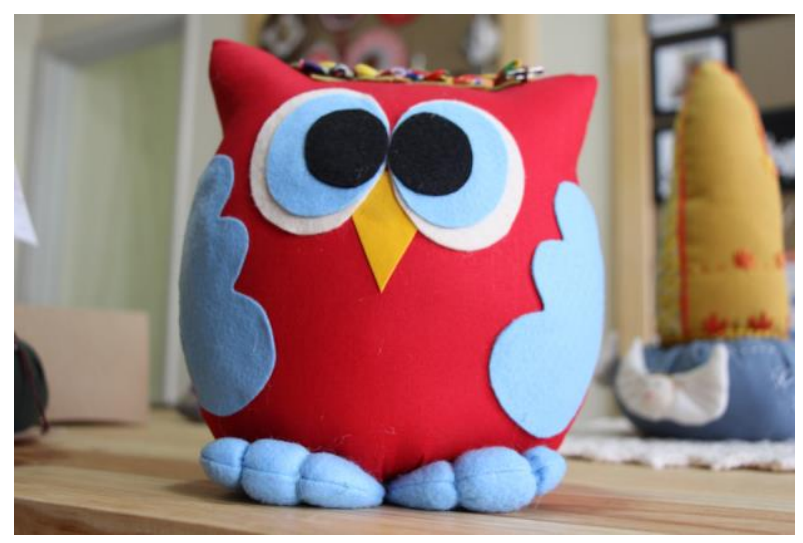

Fonte: Equipe de pesquisa (dezembro/2017)

Figura 4 - Capa porta celular e porta documentos em tecido estampado com emojis

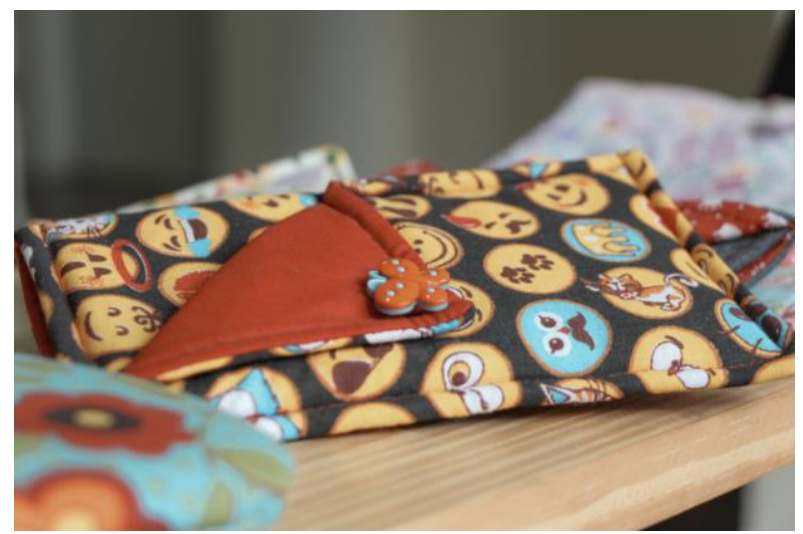

Fonte: Equipe de pesquisa (dezembro/2017) 
Figura 5 - Chinelo com pedrarias feito com técnica aprendida no YouTube

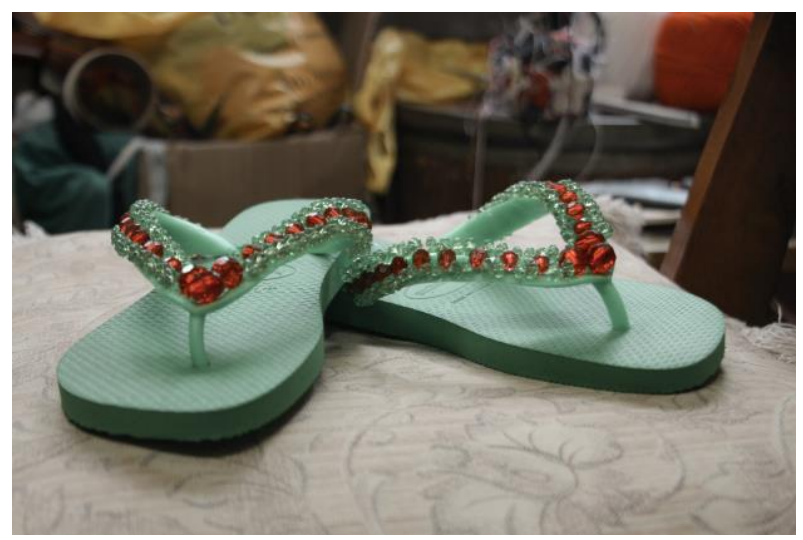

Fonte: Equipe de pesquisa (dezembro/2017)

Seria bastante precipitado tentar explicar esse fenômeno justificando que a reprodução dessas imagens nos produtos facilitaria a venda do artesanato, supondo que, ao usar figuras de produtos midiáticos de sucesso, a atenção do público seria atraída. Nesse quadro, numa ação fugidia aos olhos das grades empresas, no âmbito local, ganhos seriam alcançados por meio da utilização furtiva dessas imagens.

Por certo que o artesanato não escapa das lógicas e pressões do mercado. Como atividade produtiva e de subsistência, é suposto que o interesse em produzir peças atraentes ao público esteja presente, em alguma medida, na instância de produção (TEIXEIRA et al., 2011; MARQUESAN, FIGUEIREDO, 2014; PIMENTEL et al., 2007; MAZZA et al., 2007). Além das entrevistadas destacarem que ficam atentas ao fluxo de vendas de peças para direcionarem suas produções, uma delas, Tulipa ${ }^{7}$, explica que essas produções com influências midiáticas, além de alcançarem boas vendas, desempenham um importante papel: seja pelo interesse das crianças, seja pela curiosidade que despertam, tais peças atraem mais clientes e turistas para as lojas.

Além disso, o lugar do artesanato na realidade socioeconômica local não pode ser negligenciado, afinal, como discutido por Yúdice (2006), a cultura vem sendo compreendida, cada vez mais, pelo seu potencial de oferecer alternativas a questões prementes do social, se tornando um recurso no contexto contemporâneo. Na sua abordagem, Yúdice destaca o surgimento de iniciativas voltadas não somente para a geração de renda e promoção de

\footnotetext{
${ }^{7}$ Ao longo das entrevistas narrativas são expostas questões privadas e de tom muito pessoal acerca da vida das entrevistadas, suas condições familiares, econômicas e de saúde. Por isso, para preservar-lhes a identidade, optamos por trocar seus nomes por nomes de flores.
} 
melhorias nas condições sociais, como entende que essas ações abrem espaços para a participação cívica.

Quando à essa dimensão, entre as artesãs, é tematizado não somente o papel do artesanato na geração de renda, mas também na conquista de uma autoestima social, pois, como explica Magnólia, vive-se o orgulho de produzir algo bonito, admirado e desejado pelo outro ("o mais marcante para mim no artesanato foi quando eu vendi a minha primeira peça. A pessoa falou 'Ai, que lindo, vou levar!'. Eu me senti feliz, [...] no meio de tantas coisas bonitas, achar a sua é legal!"); bem como um suporte na luta cotidiana contra a depressão, envelhecimento e a solidão - que as leva a afirmar que o artesanato "ocupa a cabeça". Também é ressaltado pelas entrevistadas uma mudança na autopercepção, uma vez que elas passam a se sentir mais integradas à cidade, reconhecendo-se como membros de uma comunidade simbólica - produtiva e significativa - capaz de afetar a paisagem cultural local e atuar na constituição da identidade cultural marianense.

Dessa maneira, nosso objetivo não é negar a relevância econômica do artesanato nessas ambiências atravessadas pelas lógicas do turismo - afinal, elas fazem parte do emaranhado de relações nas quais essas práticas se inscrevem. Diferente disso, consideramos que olhar para elas somente por esse viés pode reduzir o potencial de significação das formas culturais inscritas nestes contextos. As formas culturais, mesmo quando apreendidas em seus substratos, transcendem seu valor econômico, pois dizem de formas de ver e se relacionar como o mundo.

Em nossa abordagem, compreendemos as formas culturais como construções simbólicas, "inseridas em contextos e processos sócio históricos específicos dentro do quais, e por meio dos quais, são produzidas, transmitidas e recebidas" (THOMPSON, 1995, p. 181). Nos processos de produção, transmissão e recepção, as formas culturais são continuamente assimiladas e reproduzidas, sendo reconfiguradas pela dinâmica de circulação e troca no ambiente social.

Tal processo de circulação é explicado por Hall (2003), para quem os processos de produção de sentido na sociedade operam numa lógica circular, de modo que não podemos olhar para os momentos de produção ou de recepção como separados ou independentes (embora operem em lógicas singulares). Encontrar traços da cultura midiática em formas artesanais traz um potencial analítico interessante para o entendimento da dinâmica cultural. Esses produtos não são meras réplicas de formas midiáticas com vistas ao lucro ou mesmo como prova de tomada do popular pelo massivo, tampouco são meros reflexos do que circula 
na mídia no âmbito da cultura popular - eles se constituem enquanto práticas significativas entretecidas a partir dos tensionamentos e das experiências cotidianas da vida social.

De nossa parte, procuramos avançar numa abordagem que observe como as formas midiáticas são internalizadas e traduzidas nas formas culturais, ressignificadas em seus consumos e reproduções, e podem, em alguma medida, revelar pistas sobre os intercâmbios, reproduções e ressignificações do popular no cenário contemporâneo. Com isso, ao invés de pensarmos em termos de perdas de referências quando observamos as marcas do midiático em produções artesanais, questionamos o que esses elementos podem revelar da ambiência social em que ganham sentido.

Partindo dessa perspectiva, nos sentimos instigados a compreender o que o atravessamento dessas formas midiáticas e sua reprodução em práticas culturais artesanais pode revelar. Neste artigo, somos guiados pela tentativa de estabelecer uma reflexão conceitual sobre esse contexto que nos auxilie a compreender a lógica cultural que engendra e alicerça o surgimento de tais formas.

\section{O MIDIÁTICO E A CULTURA POPULAR: CRUZAMENTOS E TENSÕES}

Pelos cruzamentos do midiático no âmbito das práticas culturais artesanais apresentadas acima, somos conduzidos a refletir sobre como o midiático afeta as culturas populares e quais as implicações desse fenômeno. Se houve um momento em que o debate sobre a pureza das culturas populares parecia superado, especialmente após a emergência e fortalecimento dos estudos culturais latino-americanos, basta olhar para as definições de artesanato que circulam entre os documentos elaborados para a implantação de políticas públicas no Brasil para colocarmos essa premissa em xeque. Exemplo disso é a Base Conceitual do Artesanato Brasileiro, publicada pelo Programa do Artesanato Brasileiro (PAB), em 2012, um programa criado pelo Governo Federal com o intuito de elaborar políticas públicas para estimular a produção artesanal. O objetivo maior desse tipo de iniciativa é orientar os artesãos para o empreendedorismo e para a geração de renda local.

Nesse documento, são oferecidas definições de artesanato, estabelecendo clivagens entre as atividades artísticas, artesanais e trabalhos manuais. É considerado artesão aquele que realiza produções vinculadas a uma dimensão cultural evidentemente ligada ao contexto local. Seu trabalho deve ser essencialmente manual, embora o uso de tecnologias e máquinas seja aceito - com a ressalva de que o caráter criativo precisa ser próprio, mesmo que dê origem a 
várias peças semelhantes. Aliás, a produção de peças semelhantes para a venda é aceita e estimulada, desde que a técnica seja fruto da criatividade do artesão, resultante de influências e aprendizagens desenvolvidas no contexto local, junto de seus pares, e não derive de um modelo de produção em série. Nessa lógica, configura-se como produto artesanal

todo produto resultante da transformação de matérias primas, com predominância manual, por indivíduo que detenha o domínio integral de uma ou mais técnicas, aliando criatividade, habilidade e valor cultural (possui valor simbólico e identidade cultural) podendo no processo de sua atividade ocorrer auxílio limitado de máquinas, ferramentas, artesanatos e utensílios (Base Conceitual do Artesanato, 2012, p. 12).

Ainda nesse documento, fica explícito que aprendizagens midiáticas (vindas de contatos com vídeos, programas de televisão e revistas) não podem ser consideradas produções artesanais. Tal perspectiva adota uma abordagem purista, na qual aprender atividades artesanais pelo acesso a conteúdos midiáticos romperia com a ligação com os saberes locais, típicos e tradicionais do seu contexto social de emergência (tanto no que concerne ao surgimento da técnica, do estilo e tipo de produção quanto à origem da matéria prima). Restringe-se também o modo de transmissão do conhecimento, fortemente associado às relações familiares e à comunidade local. Numa tentativa de excluir outras maneiras de construir e partilhar saberes, aprendizagens derivadas da experiência midiática são desvalorizadas, uma vez que os produtos daí derivados são considerados trabalhos manuais e não artesanais.

Os trabalhos manuais ocupam uma posição inferior com relação ao artesanato por serem "produtos baseados em cópias, sem valor cultural, que identifique sua região de origem ou o artesão que o produziu (...) [pois] recebe influência global" (Base Conceitual do Artesanato, 2012, p. 14-15). Em contrapartida, ao definir a arte popular, ressalta-se que devem ser peças únicas para manter o seu valor (numa associação ao hic et nunc - o aqui e agora da obra de arte (Cf. BENJAMIN, 1986)), mas sua vinculação ao contexto contemporâneo e globalizado é aceito e reconhecido como parte do processo criativo.

O lugar da mídia e as influências e interferências de um cenário "global" são tomados, então, numa ambivalência. Ao mesmo tempo que são tidas como relevantes enquanto característica das produções artísticas - evidenciado sua vinculação com o contemporâneo -, imprime desvalor às produções artesanais, rebaixando-as a trabalhos manuais caso o artesão se valha dessas referências e aprendizagens nas suas atividades criativas. Essa percepção, inclusive, aparece na fala de algumas artesãs que, ao mesmo tempo em que se sentem atraídas 
pelas novas possibilidades interativas e aprendizagens midiáticas, fazem questão de destacar que só se valem desses saberes em articulação com suas próprias maneiras de fazer: todas elas afirmam que não realizam "cópias" nem usam integralmente os "moldes", fazendo ajustes, remodelações e reapropriações a partir dos seus saberes locais. Isso se torna, inclusive, uma estratégia argumentativa de valorização da autenticidade das próprias produções. Conforme Jasmim, 61 anos, explica: "quando pego um molde, costumo modificar (...) artesão gosta mesmo é de modificar, fica uma coisa mais da gente".

Chartier (1995) pondera que essa percepção purista de cultura popular - vinculada somente ao dito tradicional e local - está assentada, especialmente, numa forma conservadora de tratar as culturas populares, pois "supõe-se que os novos instrumentos da mídia tenham destruído uma cultura antiga, oral, comunitária, festiva e folclórica, que era, ao mesmo tempo, criadora, plural e livre" (p. 181). Essa maneira de compreender o midiático separa-o da cultura popular. Com isso, trata a mídia como uma instituição externa à cultura e à vida social. Essa visão limitante da mídia a supõe capaz de retratar a cultura e a sociedade a partir de um lugar exterior à própria dinâmica social. A mídia figura como uma influência distanciada da cultura popular e sua presença é reduzida ao que se compreende como os meios de comunicação: rádio, revistas, jornais, televisão e internet. Nesse quadro, as aprendizagens midiáticas tendem a ser excluídas das práticas artesanais, afinal elas imprimiriam suas marcas nos saberes criadores da produção cultural. Negligencia-se que o midiático opera como uma processualidade capaz de afetar as relações sociais, bem como interfere na construção dos referenciais simbólicos e nas aprendizagens sociais.

Martín-Barbero (2003) tem se dedicado a refletir sobre tais aprendizagens, emergentes em um contexto no qual o midiático marca, cada vez mais, nossa experiência na vida social. Para ele, vivemos, na contemporaneidade, uma deslocalização e destemporalização dos saberes. Isso significa que as instituições responsáveis pela transmissão dos saberes (como a escola e a família) já não podem mais ser consideradas as únicas a exercerem essa função. Mais do que isso, com a pluralidade de fontes de acesso a informações e desenvolvimento de processos cognitivos complexos e diferenciados, essas instituições vêm, cada vez mais, concorrendo com outras instituições na transmissão dos saberes e sofrendro com uma reconfiguração nas formas de aprendizado (MARTíN-BARBERO, 2003). No contexto atual, essas novas aprendizagens promovem trocas e hibridações mais intensas e estimulam identificações para além das inserções mais imediatas ou territoriais. 
Isso é salutar entre as artesãs: elas destacam que, embora tenham tido os primeiros contatos com o artesanato na família e nas relações locais, a complementação e aprimoramento do seu fazer é, hoje, estreitamente ligado às redes sociais digitais e às interações midiatizadas - que acabam redirecionando-as para as relações locais, nas quais elas trocam as descobertas e dicas sobre aplicativos e referências midiáticas. Quanto a isso, Jasmin conta: "aprendi [crochê] mesmo com minha vizinha, depois ensinei minha mãe - ela tem 91 anos e faz artesanato. Eu aprendi o básico, né, e hoje eu sigo aprendendo. Eu comprava revistas, mas, hoje em dia, na internet é muito mais fácil. A gente vê as pessoas fazendo...". Amarilis, 75 anos, adepta ao uso das novas tecnologias, relata que adquiriu um set-up box 8 para assistir ao YouTube na televisão e aprimorar seus conhecimentos sobre a produção artesanal: "Agora eu tenho um aparelho que mostra o YouTube na televisão: é só ligar na internet e eu vejo quase 200 canais (...) eu comecei a ver os vídeos na internet e aprendi muita coisa, nessa cabeça tem muita coisa!”.

Somada a discussão das novas aprendizagens, não podemos deixar de criticar a visão limitante do lugar das tecnologias apresentada em uma abordagem purista sobre o artesanato. Subjaz a esta perspectiva uma noção instrumental das tecnologias que não problematiza dimensões mais complexas que envolvem aprendizagens e invenções, que alteram os rumos e os campos de sensibilidades criativas, capazes de incorporar, para além do instrumento, um redesenho nas relações. Para essa perspectiva, os meios de produção são separados das produções mesmas, como se essa afetação pudesse ser reduzida ou controlada, pois elas são entendidas como meros utensílios que facilitariam a produção artesanal.

Com essa visão instrumental, colocam-se restrições ao lugar ocupado pelas tecnologias na produção artesanal com o intuito de afastar a possibilidade de interferência nos processos criativos. Supõe-se que ao reduzi-las a meros instrumentos facilitadores das condições de produção, as tecnologias não seriam capazes de afetar as sensibilidades artísticas e criadoras do artesanato. No entanto, já sabemos desde Benjamin (1986) que a técnica reconfigura o processo criativo. Para ele, as percepções são afeitas às alterações das condições sociais nas quais se fundam, afinal, "o modo pelo qual a percepção humana se organiza - o meio com que ela acontece - não é apenas naturalmente, mas também historicamente determinado" (BENJAMIN, 1986, p. 285).

\footnotetext{
${ }^{8}$ Set-up box é um aparelho que permite que televisores que não são conectados à internet possam se integrar à rede e disponibilizar o acesso a canais e aplicativos como YouTube, GloboPlay, Amazon Prime, Netflix, entre outros.
} 
Percebemos também que a desvalorização das práticas culturais influenciadas pela mídia, pelas tecnologias e pelo contexto mais amplo (que escapa aos limites das relações localizadas) está associada a uma leitura territorial do artesanato. Quando Canclini (2015) discutiu as culturas populares, além de ressaltar que elas se tratavam de culturas de mescla, hibridizadas, e, portanto, impuras, também colocou em discussão um contexto no qual essas práticas e produções vinham sendo desterritorializadas.

Para Canclini (2015), a desterritorizalização é um fenômeno no qual as práticas e produtos culturais perdem a sua relação natural (ou melhor, naturalizada) com seu território geográfico. Há, inclusive, uma circulação das peças artesanais para além do seu local de origem, sendo comercializadas em territórios distantes da sua ambiência de produção. Isso aparece com certo tom de lamento na fala de Íris, artesã e funcionária de uma loja de artesanatos, para quem "antigamente, o artesanato era mais valorizado no seu valor cultural, o pessoal comprava mais tapete de sisal [produto considerado típico da região de Cachoeira do Brumado, distrito de Mariana]. Dava muito valor para as pedras. Hoje em dia, a maioria olha para as pedras e não dá muito valor, porque com essa globalização todo lugar tem tudo...”. Isso evidencia que tais práticas e produções desorganizam a rápida associação entre o popular e uma identidade local e revelam as relações multidirecionais e interculturais que vêm sendo travadas na contemporaneidade.

As produções culturais locais trazem em si a mescla não somente de elementos de culturais de outras ambiências sociais como passam a figurar em outros contextos, sendo apropriadas e recontextualizadas de maneiras plurais. Assim, não faz sentido pensar em culturas puras, capazes de revelar as tradições por si mesmas: todas as práticas seriam híbridas e fruto de relações cruzadas no tecido social. Nas palavras de Canclini,

todas as culturas são de fronteira. Todas as artes se desenvolvem em relação com outras artes: o artesanato migra do campo para a cidade; os filmes, os vídeos e canções que narravam acontecimentos de um povo são intercambiados por outros. Assim, as culturas perdem a relação exclusiva com seu território, mas ganham em comunicação e conhecimento (CANCLINI, 2015, p. 348).

Tal posição questiona a ideia de que haveria uma pureza intocada e estável no cerne das culturas populares, capaz de revelar a identidade de um povo, bem como entra em choque com as intenções de preservação dessas culturas populares das influências midiáticas. Com isso, além de podermos criticar o lugar concedido ao midiático, ao tecnológico e às vinculações territoriais na produção artesanal, ressaltamos que no pano de fundo dessa 
compreensão vigora a ideia de que a cultura popular está sempre em risco de ser sufocada e subtraída em suas características pelo midiático. Dessa perspectiva - traduzida numa tentativa desesperada de limitar e controlar os âmbitos de afetação dessas instâncias nas práticas culturais populares - emerge uma leitura redutora da própria cultura. Ela é tomada como um substrato estável, tradicional e anterior ao contemporâneo, sendo um manancial de referências sobre o povo e sua identidade, desconsiderando sua dimensão viva e porosa à ação social.

Para Chartier (1995), as formas de compreender a cultura popular têm se desdobrado, comumente, em três vias: a cultura popular pode ser definida pelo contraste que ela exprime em face da cultura dominante; pela definição de quem é seu público e seus produtores; e pelo seu potencial de trazer expressões sociais "puras", intrinsecamente populares. Assim, as maneiras de se definir e compreender a cultura popular não só são elaboradas em comparação com a cultura dominante e por um olhar externo a ela (conforme provoca Chartier, a cultura popular surge como uma categoria erudita), como a circunscreve a um grupo social e a contempla por seus substratos. Tal perspectiva, vincula a definição de cultura popular pelos objetos que ela cristaliza, sem dar conta da dimensão relacional que lhes dá origem.

Williams (2000) faz uma crítica com relação ao isso, dizendo que "uma cultura, enquanto está sendo vivenciada, não pode nunca ser reduzida aos seus artefatos, no entanto, a tentação de observar apenas a evidência externa é sempre muito forte" (WILLIAMS, 2000, p. 347). A partir deste alerta, como escapar da armadilha de procurar compreender a cultura popular através de seus artefatos? Chartier oferece uma possibilidade, enquanto propõe uma releitura da concepção de cultura popular

o popular não está contido em conjuntos de elementos que bastaria identificar, repertoriar e descrever. Ele qualifica, antes de mais nada, um tipo de relação, um modo de utilizar objetos ou normas que circulam na sociedade, mas que não recebidos, compreendidos e manipulados de diversas maneiras (CHARTIER, 1995, p. 184).

Diante disso, vamos então, avançar rumo às proposições destes autores, tentando abordar a cultura popular por meio das relações através das quais ela é vivenciada para, a partir daí, entendermos os cruzamentos do midiático com o artesanal. 


\section{RECONFIGURAÇÃO DA DEFINIÇÃO DE ARTESANATO E A RELEITURA DAS PRÁTICAS CULTURAIS}

Como apresentamos no início deste artigo, as definições de artesanato e artesão/artesã afetam a seleção de quais práticas culturais e produtos pertencem à cultura popular. Isso ocorre porque elas operam como demarcações, instaurando categorias e classificações entre as formas culturais, de modo que determinadas práticas são valorizadas enquanto outras, de caráter dissonante ou mesmo contrário aos pressupostos dessas definições, são relegadas a segundo plano e destituídas de valor cultural.

No momento em que adotamos outras perspectivas para ler o contexto social atual partindo de Canclini e Martín-Barbero - e nos associamos aos questionamentos de Williams e Chartier acerca das definições de cultura popular, torna-se necessário encontrar uma outra abordagem para refletir sobre o artesanato. Nesse sentido, temos a contribuição de Sapiezinskas (2012) que, ao problematizar o fortalecimento do artesanato da região do Cerrado, desvincula a definição de artesão das técnicas produtivas e das matérias primas envolvidas no processo de produção.

Essa autora propõe, a partir de Geertz, que as ações sociais sejam compreendidas enquanto ações simbólicas e inscritas em redes de significados compartilhados socialmente. Ela defende que os atores sociais sejam compreendidos pelas relações às quais estão envolvidos e não pelos produtos que conseguem gerar. Para ela, "uma artesã não se torna uma artesã apenas porque está empregando uma técnica artesanal, mas porque está inserida num contexto em que ser uma artesã possui um significado social em articulação com outros significados dos quais ela compartilha" (SAPIEZINSKAS, 2012, p. 134). A definiç̧ão do papel do artesão e do artesanato é vista então como marcada pela experiência social, pelas relações culturais mais amplas vivenciadas por esses sujeitos. Mais do que definir essas atividades pelas técnicas e produtos, foca-se na tessitura das relações que permite a emergência de tais ou tais formas culturais. Por meio dessa perspectiva, os produtos artesanais não são definidos pelas suas características, mas sim pelo potencial simbólico que conjugam no contexto social que lhes envolve. Consequentemente, ao notarmos o entrecruzamento das práticas artesanais com o midiático, somos estimulados a problematizar o que tais mesclas podem revelar sobre o panorama cultural contemporâneo.

De nossa parte, consideramos que essas interferências do midiático nas relações sociais e nas práticas culturais não se impõem, sufocando e anulando as formas e 
ordenamentos culturais. Trata-se de um movimento de remodelação dessas lógicas dominantes a partir de ações e astúcias no ato do consumo - ou uso. A sua maneira, Dália explica sobre importância dessa teia de relações enquanto constitutiva da ação cultural: "a gente trabalha muito em grupo, monta uma exposição e todo mundo vende, todo mundo sai feliz"; já sobre a produção, ela acrescenta "olho na revista, na televisão... a gente troca com os amigos, empresta modelos".

Com essa percepção, discute-se não um processo de dominação ou supressão das práticas culturais populares: problematiza-se o que as pessoas fazem com as referências que acessam; tematiza-se os usos e apreensões imprevistos criados pelas ações interpretativas desses sujeitos. Não se trata, portanto, de uma submissão diante da força do midiático; antes, revela um jogo de "fazer com" (CERTEAU, 2009). Nessa forma de apropriação e criação, a cultura popular realiza seus usos, incorpora os referenciais midiáticos no seu interior, tensiona suas figurações no mundo social, subverte-lhes as formas e lhes dá novos contornos. No dizer de Certeau,

ela [a cultura popular] se formula essencialmente em "artes do fazer" isto ou aquilo, isto é, em consumos combinatórios e utilitários. Essas práticas colocam em jogo uma ratio "popular", uma maneira de pensar investida numa maneira de agir, uma arte de combinar indissociável de utilizar (CERTEAU, 2009, p. 41).

Tal utilização não segue as regras prescritas pelas definições de artesanato, nem pela circunscrição do lugar do midiático. A arte da utilização se revela fora do plano previsto, desliza o lugar primeiro desses referenciais ao colocar em xeque as definições do que se configura ação popular. Considera-se, portanto, o popular como uma ação capaz de articular intervenções, enquanto prática social. Esses usos se processam a partir da inventividade e da criatividade na mescla de referências, valendo-se tanto do midiático quanto dos repertórios culturais mais amplos, compartilhados socialmente.

Nesses cruzamentos são promovidas operações próprias, capazes de imprimir traços e tensionar leituras sobre a cultura midiática, gerando formas novas para circular no ambiente social. Essas produções são consideradas por Certeau (2009) como "piratarias", "clandestinidades", formas obtusas de se valer de bens culturais e práticas, criando um outro registro para as figurações desses referenciais. Nessa arte de "fazer com", as ações são empreendidas a partir de uma leitura do contexto, de uma compreensão global da inserção dos bens culturais disponíveis à luz dos repertórios compartilhados e da criação de mesclas imprevistas. 
Certeau (2009) chama esta leitura de "senso de ocasião", ou seja, uma habilidade de saber ler o conjunto do campo de ação do dominante - no caso em tela, do cenário midiático e suas possibilidades - para tirar melhor proveito, beneficiar, enriquecer, tensionar e subverter suas práticas. Isso se evidencia no uso de imagens midiáticas para adornar ou inspirar produtos artesanais, como aquelas dos personagens Chaves ou Minions ${ }^{9}$, a despeito de todos os esforços da indústria do entretenimento de controlar os royalties de seus produtos. Nessa rearticulação das referências midiáticas, essas formas culturais encadeiam novos sentidos, muito embora não delimitem uma posição fixa: elas revelam um aproveitamento da "ocasião", um uso e um potencial de leitura que permite tirar seus proventos, ao mesmo tempo em que engendram reconfigurações das próprias práticas e estão abertas para novas proposições, novas releituras. Com isso, elas colocam em evidência as apreensões e leituras do contexto social desses outros atores.

Essas produções, capazes de articular referências cruzadas e dar origem a ações imprevistas, são, para Canclini, típicas da contemporaneidade, momento no qual "assim como não funciona a oposição abrupta entre o tradicional e o moderno, o culto, o popular e o massivo não estão onde estamos habituados a encontrá-los" (CANCLINI, 2015, p. 19). Numa ação combinatória, a cultura popular mescla e retrabalha as referências midiáticas com um repertório cultural mais amplo, dando a elas novos lugares para habitar, mostrando que o midiático e o popular se encontram num jogo de conflito e reconfiguração no campo da cultura.

Para Williams (2000), esse jogo é típico dos processos sociais de reprodução cultural. Ele considera que a cultura, mais do que ser definida por objetos, imprime uma processualidade que atravessa práticas sociais ampliadas, incluindo as artes e as produções intelectuais tradicionalmente inseridas no âmbito da cultura, bem como a publicidade, a moda, o jornalismo etc. Ao tomar a cultura como um sistema de significações realizado, ele deixa explícito que a cultura é o terreno no qual a ordem social é apreendida, comunicada, reproduzida e reconfigurada.

Os processos de reprodução cultural, para Williams, não são mera réplica de formas culturais já circulantes na sociedade, mas um momento conjugado à produção, de modo que

\footnotetext{
${ }^{9}$ Os Minions são personagens secundários presentes na animação "Meu Malvado Favorito" (2010) - e suas demais sequências - produzido pela Illumination Entertainment e distribuído pela Universal Pictures. Tais personagens alcançaram grande apreço junto ao público e, devido a isso, em 2015, foi lançado o filme de spin-off dedicado a eles. Está prevista a estreia do novo filme dessa franquia, intitulado "Minions 2: A Origem de Gru", para 2021
} 
"as ordens sociais e culturais devem ser encaradas como se fazendo ativamente: ativa e continuadamente, ou podem muito rapidamente desmoronar" (WILLIAMS, 2000, p. 198). Destaca-se, assim, não somente o caráter ativo e criador dos processos de reprodução cultural, como a dinamicidade desse processo, no qual a reprodução é alimentada e reconfigurada pelas modificações vivenciadas no âmbito social. O processo de reprodução cultural é então compreendido como resultante de tensões e conflitos entre as formas residuais (obras tradicionais anteriores ainda acessíveis) e emergentes (obras de tipos variados), englobando as ações criadoras e inventivas dos sujeitos na vida social.

Com isso, as produções que surgem no âmbito do artesanal mesclando referências e saberes do midiático podem nos levar a compreender não somente as ações criativas empreendidas no âmbito da cultura popular, como também a refletir sobre os processos sociais de reprodução e produção cultural.

\section{CONSIDERAÇÕES FINAIS}

$\mathrm{Na}$ abertura desse artigo, mostramos que a própria força do objeto nos traz inquietações: como compreender as figurações do midiático no âmbito do artesanal? Ao trazer personagens de sucesso e elementos diversos da cultura da mídia e novos modos de aprendizagem para dentro dessas práticas tidas como tradicionais, surgem questionamentos sobre as conformações da cultura popular e o contexto contemporâneo de entrecruzamento e mescla cultural.

Numa leitura conservadora do fenômeno, é recorrente a compreensão de que interferências do moderno e/ou do midiático nas formas culturais populares é sinônimo de perda. Tal perspectiva, assentada numa compreensão limitada da própria cultura, a toma como um manancial fixo e estável, um repositório das identidades culturais sociais, capaz de alimentar as práticas culturais ao longo do tempo. Supõe-se a existência de tradições a serem preservadas, de um núcleo duro, essencial, no qual essas referências poderiam ser buscadas para sustentar as produções atuais.

Essa perspectiva adota também uma visão instrumental das tecnologias, pois acredita ser possível apartá-las do processo criativo - uma vez que as entende somente como “instrumentos facilitadores" da produção, cujo uso não impactaria negativamente na criatividade do artesão. Em contrapartida, supõe-se que o midiático imprime uma 
interferência que sufoca as especificidades do local e lhes retira a singularidade, afinal ele é visto como um campo externo à própria cultura.

No afã de encontrar categorias e classificações para as práticas culturais populares e escaloná-las num sistema de valor - hierarquizando-as entre arte popular, artesanato e trabalho manual - essa leitura torna opaco o contexto social no qual tais práticas se inscrevem. Ao mesmo tempo em que tenta supervalorizar um ideal de tradição e de pureza cultural e circunscrever a cultura a seus artefatos, assenta-se no pressuposto de que é possível separar o tradicional, o moderno e o midiático na contemporaneidade.

No entanto, as culturas não trazem em seu interior territórios, repertórios e temporalidades assim tão separadas. O contexto atual é marcado pela mescla, pela hibridização, e esta característica afeta e marca as formas de reprodução cultural (CANCLINI, 2015; MARTÍN-BARBERO, 2003).

Assim, em nossa abordagem - amadurecida pelo contato com as artesãs e as produções artesanais analisadas -, colocamos em xeque essa visão purista da cultura popular por considerarmos a cultura como uma dimensão viva, marcada pela experiência social e pelo cruzamento de referências. Nela, os movimentos de reprodução, como quer Williams (2000), não podem ser separadas de uma ideia de produção e atualização. A cultura não existe estática nem nos seus substratos, ela se dá a ver nas relações de produção de sentido, nas criações e inventividades dos sujeitos: emerge dos usos, das "piratarias" e das "clandestinidades". A cultura só pode ser entendida se levarmos em conta a atuação dos sujeitos nos processos de significação e elaboração das formas culturais.

Essas formas surgem dos ensejos de se "fazer com", numa mescla imprevisível e criadora, que não respeita as fronteiras nem as expectativas do que cabe no tradicional, no moderno ou no midiático. Assim, mais do que olhar para os objetos que surgem no âmbito da cultura popular para defini-la, é preciso tentar apreender as relações culturais a partir das quais eles se fundam.

Essa abordagem, para além das implicações conceituais aqui tratadas, exige mudanças também na forma de analisar a cultura popular. Ainda que a primeira inspiração para esse estudo tenha surgido da força dos próprios produtos artesanais, a compreensão do fenômeno não pode se restringir a uma análise deles. As relações tecidas no seio da cultura popular atravessam toda a situação complexa na qual essas produções emergem: elas envolvem desde o ambiente em que esses produtos se inscrevem para ter contato com seus públicos até as relações produtivas anteriores a sua chegada nas lojas de artesanato. 
Somado a isso, há um contexto social mais amplo, no qual o surgimento desses produtos e a interação entre produtores e públicos faz sentido. Vislumbramos então aqui um ganho metodológico para o estudo das práticas culturais populares: é preciso apreender a figuração dessas práticas inscrita em uma situação comunicativa complexa, envolvendo não só os produtos artesanais, mas também a circularidade das relações culturais nas quais estão envolvidos. A operacionalização desta abordagem se abre como um desafio colocado para os estudos de Comunicação e Cultura Popular.

\section{REFERÊNCIAS}

BASE CONCEITUAL DO ARTESANATO BRASILEIRO. Programa do Artesanato Brasileiro, Governo Federal, Brasília, 2012. Disponível em: http://www.desenvolvimento.gov.br/arquivos/dwnl_1347644592.pdf Acesso em: 12/03/2017.

BENJAMIN, Walter. Magia e técnica, arte e política: ensaios sobre literatura e história da cultura. São Paulo: Brasiliense, 1986.

CANCLINI, Néstor-Garcia. Culturas híbridas. São Paulo: Edusp, 2015.

CERTEAU, Michel de Cultura no plural. Campinas: Papirus, 2008.

CERTEAU, Michel de. A Invenção do Cotidiano: Artes do fazer. Vol.1 Petrópolis: Vozes, 2009.

CHARTIER, Roger. Cultura popular: revisitando um conceito historiográfico. Estudos históricos, Rio de Janeiro, v.8, n.16, p.179-192. 1995.

HALL, Stuart. Da Diáspora: identidades e mediações culturais. Belo Horizonte: Editora UFMG, 2003.

MARQUESAN, Fábio. F. FIGUEIREDO, Marina Dantas. De artesão a empreendedor: a ressignificação do trabalho artesanal como estágio para a reprodução de relações desiguais de poder. Revista de Administração Mackenzie, São Paulo, v.15, n.6, Edição Especial, p.76-97, Nov./Dez. 2014. Disponível em: http://www.scielo.br/pdf/ram/v15n6/1518-6776-ram-15-06-0076.pdf Acesso em: 05/10/2017.

MARTÍN-BARBERO, Jésus. Saberes hoy: diseminaciones, competencias transversalidades. Revista Iberoamericana de Educación. Madri, n. 32, p.17-34, 2003.

MAZZA, Adriana. IPIRANGA, Ana Silva. FREITAS, Ana Augusta. O design, a arte o artesanato deslocando o centro. Cadernos Ebape.br, São Paulo. v.5. n.4, p.1-11, Dez/2007.

PIMENTEL, Thiago Duarte; CARRIERI, Alexandre de Pádua; LEITE-DA-SILVA, Alfredo Rodrigues; ABATE JUNIOR, Cláudio Borges. Mudanças simbólicas: análise discursiva das transformações identitárias e espaciais em uma feira. Cadernos Ebape.br, São Paulo, v.5, n.1, p.1-23, 2007. 
SAPIEZINSKAS, Aline. Como se constrói um artesão. Horizontes Antropológicos, Porto Alegre, ano 18, n. 38, p. 133-158, jul./dez. 2012. Disponível em: http://www.scielo.br/scielo.php?pid=S010471832012000200006\&script=sci_arttext Acessado em: 05/10/2017.

TEIXEIRA, Marcelo et al. Artesanato e desenvolvimento local: o caso da comunidade quilombola de Giral Grande, Bahia. Interações, Campo Grande, v. 12, n. 2, p. 149-159, jul./dez. 2011. Disponível em: http://www.scielo.br/pdf/inter/v12n2/a02.pdf Acessado em: 05/10/2017.

WILLIAMS, Raymond. Cultura. Rio de Janeiro: Paz e Terra, 2000.

YÚDICE, George. A conveniência da cultura: usos da cultura na era global. Belo Horizonte: Editora UFMG, 2004.

\section{Original recebido em: 02 de agosto de 2018}

Aceito para publicação em: 24 de abril de 2020

\section{Denise Figueiredo Barros do Prado}

Professora do Departamento de Jornalismo e do Programa de Pós-Graduação em Comunicação da Universidade Federal de Ouro Preto (UFOP). Doutora em Comunicação pelo Programa de Pós-Graduação em Comunicação Social da Universidade Federal de Minas Gerais (UFMG), com estágio doutoral na École des Hautes Études en Scieces Sociales (EHESS/França). Realiza Pós-Doutorado no Programa de Pós-Graduação em Comunicação e Cultura na Universidade Federal do Rio de Janeiro (UFRJ). Líder do Grupo de Pesquisa em Mídia e Interações Sociais - Giro.

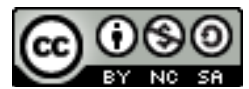

Esta obra está licenciada com uma Licença

Creative Commons Atribuição-NãoComercial-CompartilhaIgual 4.0 Internacional 